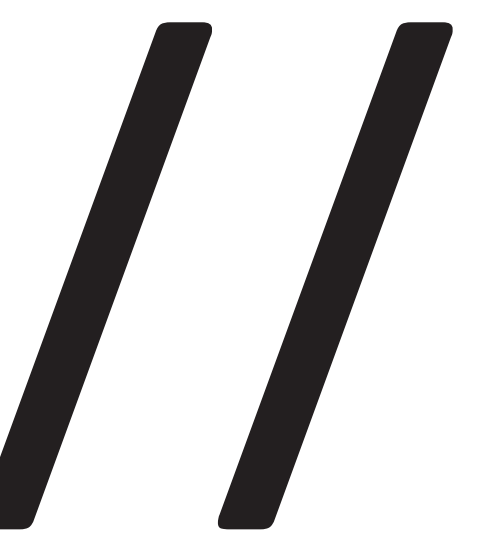

\title{
Narrativas de uma viagem permanente: a produção filmica de Herbert Duschenes
}

Narratives of a permanent journey: the films of Herbert Duschenes

Paola Prestes Penney ${ }^{1}$

${ }^{1}$ Documentarista pela Serena Filmes e doutoranda na Universidade de São Paulo, Escola de Comunicações e Artes, Programa de Pós-graduação em Meios e Processos Audiovisuais. Pesquisa realizada com apoio do Centro Cultural São Paulo e do Instituto Itaú Cultural. E-mail: paola. prestes@usp.br 
Dossiê $A$ pesquisa em cultura audiovisual: novos desafios e aportes teóricos Narrativas de uma viagem permanente: a produção fílmica de Herbert Duschenes | Paola Prestes Penney

Resumo: este artigo aborda os filmes realizados por Herbert Duschenes, arquiteto e professor de história da arte alemão radicado no Brasil em 1940. Nunca antes estudados e assistidos apenas por amigos, membros da família e por alunos, nosso objetivo é conferir aos filmes uma leitura que vai além do âmbito doméstico e didático que lhes foi originalmente reservado, analisando-os como home movies, ou filmes amadores, pertencentes ao campo do cinema documentário. Como parte da pesquisa, os duzentos e vinte sete curtas-metragens do acervo foram digitalizados e catalogados, sendo agora estudados à luz de conceitos de teóricos como Roger Odin e Arlindo Machado, que têm desenvolvido pesquisas sobre esse tipo de produção, contribuindo para a reflexão acerca das fronteiras do documentário. Palavras-chave: documentário; filme amador; home movie; Duschenes.

Abstract: this article addresses the films made by Herbert Duschenes, German architect and art history lecturer who arrived in Brazil in 1940. Never studied before, to this day the films have been watched only by family members, friends and students. Our goal is to confer to the films a reading that goes beyond the domestic and didactic purposes that were originally attributed to them, analyzing them as home movies that belong to the territory of documentary. As part of the research, the two hundred and twenty seven short films of the collection have been digitalized and identified. They can now be studied in the light of concepts by Roger Odin and Arlindo Machado, whose investigations focus on this kind of production, thus fostering the debate on the boundaries of documentary film making. Key words: documentary; family film; home movie; Duschenes. 


\section{Filmes amadores, filmar por amor}

O projeto de doutorado que estou desenvolvendo na Escola de Comunicações e Artes da Universidade de São Paulo aborda os filmes do acervo Herbert Duschenes e tem origem em uma experiência pessoal, quando, na década de 1980, fui aluna de Herbert Duschenes na Fundação Armando Alvares Penteado (FAAP). O professor deixou uma marca indelével em muitos de seus alunos, entre os quais vários expoentes da Geração 80 e artistas hoje em atividade em diversas áreas. Isto se deu por um conjunto de fatores que abarcavam desde a vasta cultura e carisma pessoal do professor até o que acabou por se tornar sua indissociável e mais notável referência: os filmes que ele mesmo realizava e projetava em sala de aula, e em sua casa também, para amigos e jovens que não tinham meios de frequentar uma faculdade particular. O carisma, Duschenes o levou com ele quando faleceu em Curitiba, em 2003. O material fílmico está hoje no Arquivo Multimeios do Centro Cultural São Paulo (AMM-CCSP), até este momento indisponível para consulta pública.

Os filmes se encontram em um ponto cego: para todos os efeitos, foram gerados para fins pedagógicos por um professor. Contudo, não participam do universo acadêmico em nenhuma instância. No que tange o universo cinematográfico, realizados fora dos padrões tradicionais e integralmente autoproduzidos, acabaram por se abrigar na categoria de contornos incertos dos chamados home movies, filmes amadores ou filmes de família, ainda raramente convidados a integrar o repertório oficial da cinematografia brasileira e mundial:

Podemos, com razão, nos espantar com a quase total ausência de interesse manifestado pelos pesquisadores de cinema pelos filmes e vídeos de família; ausentes dos dicionários ou das enciclopédias, ausentes das histórias do cinema assim como da teoria do cinema, o filme de família é verdadeiramente esquecido nesse grande movimento de reflexão sobre o cinema que se desenvolveu a partir dos anos sessenta (ODIN, 1995, p.5).

Esta situação por si só desperta o interesse pelos filmes que Duschenes realizou quase obsessivamente ao longo de cinco décadas. Inéditos, nunca foram estudados, nunca passaram pelo crivo da crítica especializada e tampouco foram comercializados ou projetados publicamente como um corpo de trabalho expressivo e de imanência cinematográfica: não são reconhecidos pois não são conhecidos.

Até recentemente, o suporte em película em $8 \mathrm{~mm}$. e Super $8 \mathrm{~mm}$. (considerado cinema amador) dificultava sua projeção pública e difusão. Esta pesquisa e o projeto de documentário a ela vinculado deflagraram um processo de resgate e, 
como parte dele, em 2016, o Itaú Cultural arcou com a limpeza e digitalização do acervo. Várias obras puderam ser vistas na Ocupação Maria e Herbert Duschenes que lá ocorreu entre 27 de abril e 12 de junho do mesmo ano. Esta foi a primeira projeção pública de filmes realizados por Duschenes e espera-se que o acervo digitalizado possa doravante ser exibido mais facilmente e acessado em plataformas on-line. Contudo, a digitalização em si é um processo técnico que, sozinho, não revela o acervo como um corpo de trabalho pertencente ao campo do cinema. Portanto, esta tese é o primeiro gesto no sentido de romper esse impasse criando um canal que introduzirá os filmes tanto no universo da pesquisa acadêmica como naquele da produção audiovisual, apresentando-os como um significativo material de referência da cinematografia brasileira.

Há outro motivo a justificar o interesse pelo acervo Duschenes. Estudar filmes amadores, ou seja, um gênero considerado marginal à produção cinematográfica industrial, significa entrar no compasso de uma das mais vigorosas tendências da produção audiovisual dos últimos anos e, consequentemente, da sua pesquisa. Esses filmes abarcam uma variedade de temas, recortes e também experimentações de linguagem, e têm gerado resultados que atestam a vitalidade e vocação para a renovação inerente ao campo do documentário, que não raro empresta esses resultados ao cinema industrial. Assim, ao obervar esses desenvolvimentos, teóricos contemporâneos como Roger Odin e Arlindo Machado têm consolidado a necessidade de olharmos com mais atenção para esse tipo de produção: "Dadas a extensão e a variedade das experiências que estão hoje acontecendo debaixo desse imenso guarda-chuva chamado documentário, é tempo de rever nossas hipóteses, nossos conceitos e nossos preconceitos sobre o que poderia estar abrigado ali” (MACHADO, 2007 p. 23).

Na Europa, notadamente na França e na Bélgica, os filmes de família e o cinema amador de um modo geral têm merecido a atenção de teóricos de outras áreas que o cinema: etnólogos e pesquisadores da área de antropologia visual têm dedicado artigos, livros e seminários a esse gênero. Nos Estados Unidos, universidades criaram laboratórios voltados não apenas ao estudo, mas à produção de filmes de linguagem autoral, ensaística e transmidiática. É o caso do Media Lab, da MIT (comandado da sua criação até 1989 por Richard Leacock) e também do Sensory Ethnography Lab (SEL) da Universidade de Harvard, cuja produção aponta para os novos rumos do audiovisual ao romper sem remorso com paradigmas do cinema industrial e do documentário clássico.

Diante dessa tendência, como não lembrar da Primeira Declaração do Novo Cinema Americano, de Jonas Mekas, quando este, ao defender um espaço autônomo 
de criação, livre das imposições de fundo e de forma do cinema industrial, estabelece como primeiro princípio: "1. Acreditamos que o cinema é, indivisivelmente, uma expressão pessoal. Rejeitamos, portanto, a interferência de produtores, distribuidores e investidores até que nosso trabalho esteja pronto para ser projetado na tela" (MEKAS; MOURÃO, 2013, p. 33). Mais adiante, no nono artigo da Declaração, ele encadeia com uma frase que poderia ter sido dita por Duschenes: "Filmes possuem o direito de viajar de um país para outro, livres dos censores e das tesouras dos burocratas" (MEKAS; MOURÃO, 2013, p. 35), e arremata com uma advertência que é quase uma provocação, "Não queremos filmes falsos, polidos, lisos - os preferimos ásperos, mal-acabados, mas vivos; não queremos filmes cor-de-rosa -, os queremos da cor de sangue" (MEKAS; MOURÃO, 2013, p. 35).

Talvez haja no manifesto de Mekas um tom de bravata próprio dos jovens artistas da década de sessenta. Nem por isso são palavras desprovidas de sentido ou substância. Elas ecoam uma visão já defendida - mais precisamente no caso do documentário - por Robert Flaherty anos antes e assim comentada por Richard Leacock:

Robert Flaherty, que fez Nanook, o esquimó, em 1921 e em seguida, com sua mulher Francis, Moana em 1925, teria dito que, eventualmente, filmes acabariam sendo feitos por "amadores". O que ele quis dizer com isso? Certamente não tinha em mente o significado que essa palavra hoje em dia implica: "incompetência". Contudo, o significado da palavra oposta também mudou, "profissional" hoje se refere a uma pessoa que foi legitimada por uma instituição como um "especialista". Nossa "indústria" (de cinema documentário) é dominada por essas pessoas, que manipulam complicados equipamentos profissionais com garantida competência; soldados marchando para a guerra. Eu acho que Flaherty queria dizer que filmes seriam feitos por pessoas que amam a arte, o ato de filmar; que amam criar sequências que fazem justiça aos seus personagens, que transmitem uma requintada sensação de ver, ouvir, de estar lá (LEACOCK, 1993).

Portanto, um cineasta amador pode ser aquele que faz filmes porque ama filmar, e não porque não sabe filmar. No caso de Duschenes, podemos falar de um cineasta que, além de amar o ato de filmar, ama aquilo que filma, da sua família ao mundo que o circunda. Quanto à execução do filme em si e seu resultado, em $O$ filme de família dentro da instituição familiar, Roger Odin comenta precisamente a questão do filme "mal feito", afirmando que "o filme de família parece destinado a uma incompletude definitiva, pois o filme de família não é um texto: é para sempre um fragmento de texto" (ODIN, 1995, p. 28). Pouco depois, ele conclui, "de fato, tanto em uma instância pessoal como coletiva, nada pior do que um filme de família 
‘bem feito"” (ODIN, 1995, p. 37). É claro que Odin não faz aqui a apologia da falta de conhecimento ou domínio técnico. Sua proposta é romper com a subordinação do filme amador aos preceitos do cinema clássico, industrial, afirmando seu direito a uma estética e construção narrativa - ou não construção - próprias, sem que isso os desqualifique como produção cinematográfica.

Essa noção oferece um ponto de partida para considerarmos os filmes de Duschenes como obras mais pensadas para o mundo do que para o núcleo familiar e, portanto, como uma produção nem tão amadora assim. Ele pode ter apontado sua câmera para a família, mas desde as primeiras obras são visíveis a intenção de construir um discurso, ou, mais precisamente, reconstruir a experiência de estar no mundo por meio das imagens, o cuidado formal e a metodologia de trabalho que alicerça a produção como um todo, da filmagem até a montagem. Temos assim os primeiros insumos para fundamentar a hipótese da pesquisa: não estamos diante de filmes de um cineasta amador apenas, mas diante dos filmes de um documentarista autodidata que ama filmar.

\section{O acervo Duschenes}

Mas, em que consiste o acervo que é objeto desta pesquisa e qual a sua origem? Parte em preto e branco, parte em cores, ele é composto por duzentos e vinte sete filmes em $8 \mathrm{~mm}$. e Super $8 \mathrm{~mm}$. (estima-se que alguns filmes tenham se perdido ao longo dos anos), sem som, tendo em média vinte minutos de duração cada, somando cerca de cinquenta horas de material montado. Foram inteiramente realizados entre as décadas de 1940 e 1980 por Herbert Duschenes, arquiteto alemão de origem judaica que se estabelece em São Paulo em 1940, casando-se dois anos depois com a coreógrafa e bailarina húngara Maria Duschenes, née Ranschburg.

Do encanto com a nova vida no Brasil tem início uma produção sistemática de filmes. É interessante notar que Duschenes chega ao Brasil apenas cinco anos depois de Claude Lévi-Strauss. Os motivos da vinda de Lévi-Strauss são de natureza diferente, mas em Tristes trópicos algumas observações remetem ao Brasil que Duschenes, teria visto por ocasião de sua chegada. Esse impacto, também descrito pelo professor em sua autobiografia, será abordado na tese, pois esse primeiro olhar que descobre aquilo que Lévi-Strauss chama de "formidável entidade", o Novo Mundo, mas também, em uma chave mais pessoal, um mundo novo, é determinante para a análise de um conjunto de filmes cuja produção se deu após essa visão, e acabaram por cumprir a função de construir uma "nova memória" de seu realizador. Esse pro- 
cesso tem como ponto de partida um sobressalto, pois, como Duschenes narra em sua autobiografia, ao chegar ao porto de Santos, ele se depara com o navio de guerra alemão Windhuk:

Entrando, já na madrugada meio clara no estuário de Santos e aproximando-nos do cais do porto, vi um navio aí ancorado. Era o quê? Nada menos do que o temido Windhuk, cuja tripulação também a caminho de Montevidéu se deu conta do suicídio para o qual caminhava e desistiu. Desertou, o Windhuk se entregou à Marinha do Brasil (DUSCHENES, 2003).

Duschenes e Maria, ambos de origem judaica, escaparam do nazismo - e provavelmente da morte - graças a uma viagem. Portanto, a vinda para o Brasil (onde se conheceram) não é fortuita e não tem nenhuma relação com o turismo ou o lazer. Este primeiro e fundamental deslocamento geográfico pauta outros deslocamentos, como o do olhar do professor-cineasta sobre o mundo e, por fim, endossa o deslocamento do olhar do espectador - ou leitor - sobre os filmes hoje. Em Às origens do cinema: o filme de família, Eric de Kuyper se refere a quem assiste a filmes de família não como espectadores, mas testemunhas. É uma alusão ao jogo de olhares que se instaura entre quem filma, quem é filmado e, posteriormente, quem assiste, e cuja dinâmica é o compartilhamento de uma experiência vivida, via de regra, uma experiência feliz (ODIN, 1995, p. 16).

No caso dos filmes de Duschenes, a felicidade de que somos testemunhas não é prosaica, tampouco um elemento da vida cotidiana a ser tomado como certo, ou um registro corriqueiro que ficará circunscrito aos arquivos mnemônicos da família. Ao interpretar os filmes, é preciso levar em conta a história social que engendra a sincronia que, como em uma sinistra montagem paralela, acompanha a sua realização: no momento em que Duschenes começa a filmar no Brasil, milhões de homens, mulheres e crianças como ele, Maria e seu filho Ronaldo, ou Ronny (sua filha Silvia nasceria alguns anos mais tarde) são assassinados em campos de extermínio na Europa. É esse o negativo das imagens que a elas adere como uma indissociável sombra. Assim, filme após filme delineia-se a sensação que Duschenes não está filmando e montando no presente, mas no futuro do pretérito composto. Isto é, ele filma a vida que teria tido na Europa se esta, por causa da Segunda Guerra Mundial, não lhe tivesse sido negada. A Alemanha desfigurada, cenário de um tipo de intolerância sem precedentes e, pátria agora inacessível, dá lugar a um Brasil luminoso e sereno.

Portanto, os filmes possuem duas camadas de leitura: a primeira e talvez a mais óbvia, a revelação de um país muito diferente de sua Alemanha natal. A câmera registra estradas rurais, estações de trem, placas com os nomes das cidades, caipiras, 
caiçaras, fauna, flora, praias desertas e a luz intensa dos trópicos em planos que se detêm no céu, entregando-se a um olhar de desfrute. Na década de 1940, o ponto de vista de Duschenes ainda é extremamente eurocêntrico e é nesse cenário redentor que Duschenes filma atividades tipicamente alemãs como o Waldspazierengang, ou passeios em bosques nas imediações de São Paulo. Vestidos como europeus setentrionais, o grupo formado por Maria e amigos (e o próprio Duschenes, de relance, provavelmente filmado por algum amigo) percorre praias, estradas de terra e plantações de milho trajando terno e gravata, vestido e colar de pérolas. Somente o jovem Ronny às vezes troca as calças curtas e suspensórios por trajes de menino caipira ou roupa de banho para se lançar no mar do litoral brasileiro. Cada detalhe dos piqueniques na relva e do cardápio europeu é enfocado: não faltam planos fechados de maçãs, ameixas, ovos cozidos, nozes e sanduíches. Em um determinado momento, planos de Ronny com uma garrafa de Guaraná lembra o espectador - ou testemunha - que os personagens estão na Cantareira, e não na Floresta Negra ou em algum bosque europeu.

A segunda camada diz respeito ao discurso ao qual já aludimos e que subjaz à amenidade representada nas imagens. Com o passar dos anos, qualquer vestígio de superficialidade que o registro de momentos felizes pudesse sugerir esvanece perante a dimensão histórica da vida aparentemente banal de seus personagens, visto que, enquanto o Terceiro Reich e suas conquistas bélicas deixaram de existir, a conquista de Duschenes - o direito a uma vida feliz em família, ou simplesmente o direito à vida -, triunfa até hoje em seus filmes. Isto porque ele não documentou apenas seu dia a dia ou a vida em família, mas o que há de extraordinário no fato de estar vivo e ter logrado criar uma família, garantindo assim sua descendência. O registro em si é de suma importância, pois não afere primazia à memória apenas. Talvez, intuitivamente, ele compreendesse que para assegurar um futuro, era preciso criar um "novo passado" e o fez por meio de uma câmera e de uma mesa de montagem. Desse modo, cada passeio pelas estradas empoeiradas do interior paulista, cada tomada, cada expressão que ele filma do filho brasileiro e da mulher amada afirma a supremacia da vida sobre a morte. 

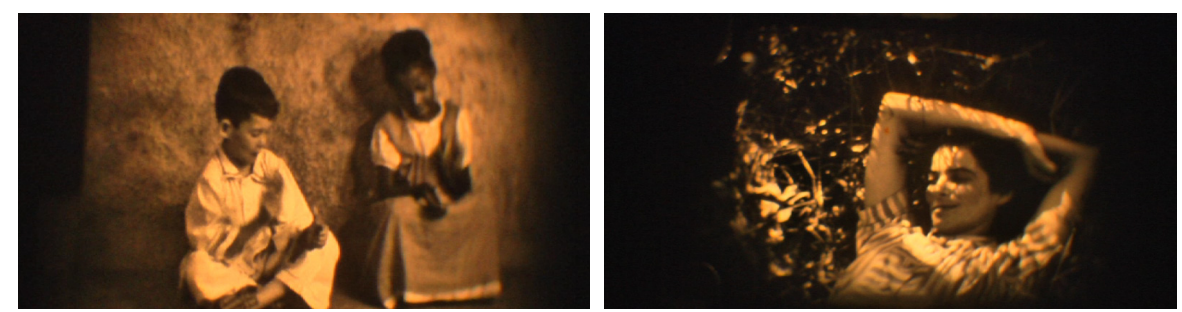

Figura 1: Acervo Duschenes, fotogramas do filme nº 218, Ronny (1949/1950)

\section{O repórter da arte}

Duschenes descobre o Brasil em São Paulo, mas também em Bertioga, São Vicente, Santos, Guarujá, São Roque, Campos do Jordão, em sítios e fazendas. Há também as viagens para a Bahia e Recife. Se, a princípio, a produção é constituída por filmes de família e, em proporção menor, filmes de viagem (gêneros cujas fronteiras não são sempre claras), a partir dos anos 1950, ocorre uma inversão e estes últimos vão se tornando o principal foco de interesse de Duschenes que, nesse processo, assume mais claramente o papel de enunciador em sua obra. Não se trata de dois tipos de produção independentes: os filmes de família já incubam os filmes de viagem na medida em que as situações filmadas em família tendem cada vez mais a se passar fora de casa.

Nas décadas seguintes, ao retomar viagens para a Europa e iniciar incursões por outros países, nasce o "repórter da arte", termo cunhado pelo próprio realizador. Assim, quando aceita o convite para dar as primeiras aulas de história da arte na Fundação Armando Alvares Penteado (FAAP) no final dos anos 1960, ele leva para a sala de aula um impressionante material fílmico de sua própria autoria: são dezenas de filmes que abordam características e manifestações artísticas, arquitetônicas, tecnológicas, religiosas e culturais em diversos países, mostradas de um ponto de vista muito particular, o ponto de vista de Herbert Duschenes. 

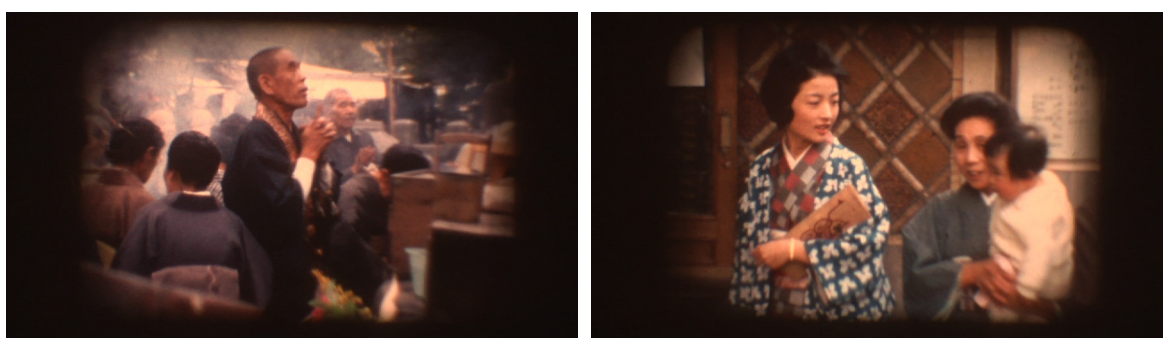

Figura 2: Acervo Duschenes, fotogramas do filme nº 89, Japan IV (1966)
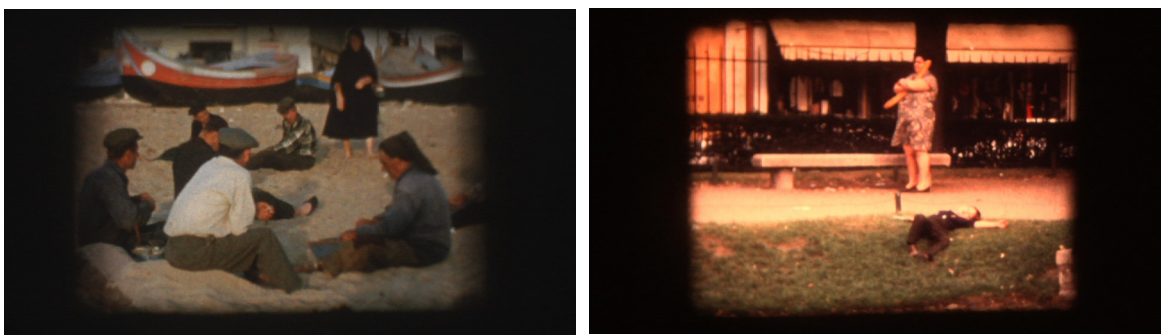

Figura3: Acervo Duschenes, fotogramas dos filmes n 56, Portugal 1 (s.d.) e n 39, Chronique de l'art vivant (1973)

Longe de serem travelogues engessados no tempo, reféns de um discurso institucional, os filmes são montados e remontados várias vezes ao longo dos anos, privilegiando um aspecto diferente de uma narrativa a cada vez. Assim, o que podemos assistir hoje não é a única montagem, mas a última. Filmados em viagens anuais que o professor-cineasta empreende, eles se multiplicam, tornando-se uma viagem permanente que se estende por décadas e no decurso da qual é tecido um comentário contínuo - porém, não linear - sobre o mundo. Esse olhar sobre a humanidade é compartilhado com seus alunos, jovens que vivem sob as restrições à informação e ao conhecimento que o governo militar da época impõe, e, é importante lembrar, ainda estão a duas décadas de ouvir falar em web ou internet.

\section{Filmar o movimento}

Da estreita relação com Maria desponta um terceiro eixo de produção: filmes de dança. Bailarina de formação, depois do nascimento do primeiro filho ela passa a dedicar-se apenas à coreografia e ao ensino da dança por conta de um caso tardio de poliomielite. O filme Hands (sem data) é um exemplo do trabalho que Maria viria a desenvolver, contornando as limitações físicas que a doença impôs. A utilização de uma cartela chama a atenção no início do filme, indicando propósitos 
para além do registro familiar. Na sequência, à maneira de Jonas Mekas, um poema escrito à máquina (provavelmente de autoria do casal) introduz o filme:

\author{
HEBERT and MARY \\ present \\ A constant driving \\ and thriving \\ always changing \\ but never dying \\ eternal flow \\ of living forms \\ which move and grow \\ which even without \\ your awareness \\ sometimes as lovely \\ and sometimes as a \\ twisted likeness \\ are mirrored in \\ your soul.
}

O cenário é o lar do casal, mas isto não fica aparente em nenhum fotograma, pois não estamos diante de um marido que filma a mulher no ambiente doméstico. Aqui, o que testemunhamos é a colaboração artística entre Herbert e Maria em um trabalho cuja concepção formal lembra em mais de um plano o curta-metragem Meshes of the afternoon (Tramas do entardecer, 1943), da também bailarina e coreógrafa Maya Deren e seu então marido Alexander Hammid.
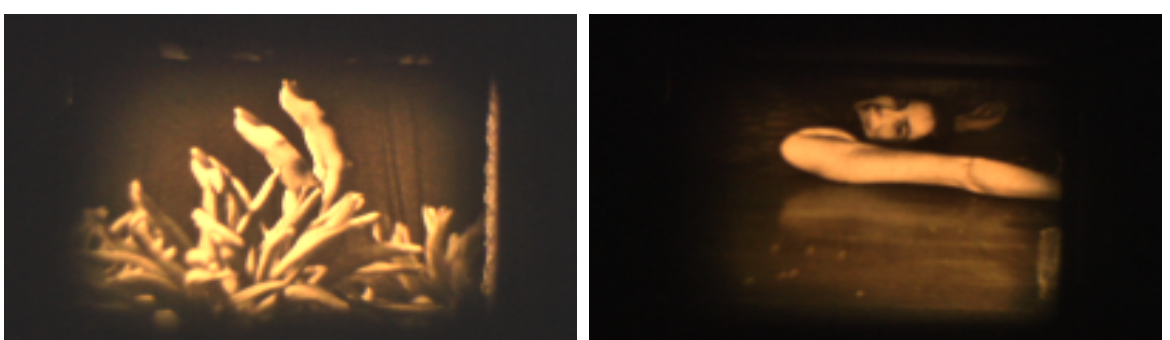

Figura 4: Acervo Duschenes, fotogramas do filme n ${ }^{\circ} 174$, Hands (s.d.) 
À medida que outros personagens vão aparecendo nos filmes, as coreografias de Maria, as improvisações de seus alunos ou simplesmente o movimento dos corpos passam a impor os enquadramentos, os planos, a escolha das tomadas, o ritmo e a dinâmica de seus encadeamentos na mesa de montagem. Com imagens raras de artistas como Juliana Carneiro da Cunha, J. C. Violla e Denilto Gomes, além de registros históricos da introdução do sistema Laban no Brasil, os filmes oferecem a possibilidade de analisarmos a captação do movimento do corpo pela câmera e sua representação cinematográfica.

Assim, mais familiarizados com o acervo Duschenes, retomamos a hipótese da pesquisa que afirma os filmes que o compõem como obras cinematográficas, pertencentes ao território do documentário, contudo, nem tanto do documentário clássico como do documentário que transcende a etimologia do seu nome ao abraçar obras que demandam uma interpretação mais arguta. Enquanto um olhar microcósmico indaga como são construídos e que tipo de linguagem resulta dessa construção, outro olhar, desta vez macrocósmico - e que inclui o olhar e a experiência de quem os viu - procura a unidade poética que os afiança como um corpo de trabalho de imanência cinematográfica. Por "cinematográfica", entendemos um tipo de produção que pertence ao campo do cinema².

A hipótese que traz esses filmes para o território do documentário dialoga com a questão mais ampla em torno da definição de suas fronteiras. Se, por um lado, a dificuldade que acompanha essa definição gera um estado de crise permanente no documentário, por outro possibilita seu estudo sob diversas óticas, expandindo sua abrangência. No presente caso, trata-se de problematizar questões relativas a um tipo de produção ainda insuficientemente estudada que floresce à margem do cinema industrial, os filmes amadores - que, no caso, compreendem filmes de família, de viagem e de dança - e, ao procurar respondê-las, enfrentar o desafio de aclarar uma fração pouco explorada do movediço território do cinema documentário.

\section{A análise de filmes inéditos}

O acervo Duschenes coloca de antemão a seguinte pergunta: como olhar para filmes que nunca foram vinculados a nenhuma referência estética ou histórica, que nunca passaram por nenhuma comparação, análise ou interpretação? Esse apa-

\footnotetext{
${ }^{2}$ Não utilizamos o termo "audiovisual", pois essa noção abarca todo tipo de produção ou conteúdo audiovisual sem distinção. Portanto, se ao desenvolvermos nossas pesquisas não delimitarmos algum tipo de área mais específica dentro do audiovisual (cinema, videoarte, documentário, filme amador, comercial de TV, vídeo clip, meme, vídeo game, etc.), podemos estar confundindo nossos objetos com conteúdos que não carecem ser afirmados como nada além de "audiovisual".
} 
rente excesso de liberdade demanda redobrado cuidado no momento de escolher uma estratégia de abordagem. Se, por um lado, estamos a salvo da tentação de tomar caminhos já muitas vezes percorridos, por outro é preciso criar os meios adequados para submeter os filmes a um primeiro processo analítico sem lesá-los. Isto porque a primeira análise de um filme se torna naturalmente o parâmetro para as reflexões que se farão subsequentemente sobre ele. Um filme inédito se oferece ao analista sem a proteção prévia de textos que afirmam e consagram uma obra cinematográfica - nem que seja pelo simples esforço de sua escrita -, e terminam por formar um tipo de couraça em torno dos objetos de análise mais conhecidos.

Salvo os escritos do próprio Duschenes (planos de aulas, cartas e uma autobiografia que ele começou a redigir no final da vida a pedido da família) e depoimentos de ex-alunos sobre seu legado como professor, não há artigos, depoimentos, entrevistas ou qualquer outro material que esmiúce a sua atuação como cineasta documentarista. Isto não chega a se uma anomalia posto que não são muito frequentes referências acerca de obras como as que ele começa a realizar na década de 1940. Talvez um dos motivos seja o fato desse tipo de produção ter sido gradualmente relegado à marginalidade quando, a partir dos anos 1930, momento em que o cinema dito de ficção já goza de um sistema de produção industrial, passam a ser atribuídas ao cinema documentário funções informativas, propagandísticas, pedagógicas ou, em termos gerais, edificantes, enquanto ao cinema de ficção, institui-se um contrato com a criação literária e artística.

A produção audiovisual amadora volta a se desenvolver de maneira expressiva a partir dos anos 1980 quando, graças ao vídeo analógico, são disponibilizados em grande escala meios de produção para não profissionais, ou seja, cineastas amadores. Menos de duas décadas mais tarde, com o advento das câmeras digitais integradas a programas de edição não linear e plataformas on-line (Youtube, Vimeo, etc.), a produção feita por esses cineastas - ou videomakers -, passa a se inserir de forma consistente, ubíqua (sedimentando a noção de transmídia) e irrevogável nos meios de comunicação. A bibliografia que passa então a ser gerada tende a privilegiar realizadores recentes, cuja produção tem início concomitantemente à popularização de câmeras de vídeo não profissionais.

Uma das características do cinema documentário é gerar filhos pródigos que, escorados pela dificuldade de definição de suas fronteiras, refutam correntes e movimentos que tentam unificar o gênero sob um mesmo conjunto de regras ou dogmas. Herbert Duschenes é um desses filhos e sua produção se desenvolve ao longo de cinco décadas, alheia às escolas ou tendências vinculadas às instituições 
governamentais, estéticas ou movimentos políticos. Seus filmes são precursores da pulverização que se dá em virtude dos meios digitais de produção, quando cada indivíduo tem o potencial de se tornar o criador de seu próprio movimento, escola ou linguagem. Ao trabalharmos com um corpus criado antes dessa retomada do filme amador (quase um século depois do surgimento do cinema que, é sempre bom lembrar, nasce registrando cenas do dia a dia), e estudarmos obras que nunca foram relacionadas a nenhuma bibliografia ou conceito específico, a fundamentação teórica torna-se particularmente estratégica.

$\mathrm{Na}$ medida em que, em razão de afinidades estéticas e conceituais, mas também do modo de produção, olhamos para os filmes de Duschenes pelo viés do documentário, talvez seja prudente retomar alguns conceitos já conhecidos, como, por exemplo, quando, ao comentar as obras dos seminais Flaherty e Grierson, João Moreira Salles aponta para a duplicidade inerente ao filme documentário, questão que diz respeito à equação que eternamente procura equilibrar o registro de um fato dito real e a marca do subjetivismo que, inevitavelmente, incide sobre a representação desse fato:

De modo geral, desde Flaherty podemos dizer que todo documentário encerra duas naturezas distintas. De um lado, é o registro de algo que aconteceu no mundo; de outro lado, é narrativa, uma retórica construída a partir do que foi registrado. Nenhum filme se contenta em ser apenas registro. Possui também a ambição de ser uma história bem contada. A camada retórica que se sobrepõe ao material bruto, esse modo de contar o material, essa oscilação entre documento e representação constituem o verdadeiro problema do documentário. Nossa identidade está intimamente ligada ao convívio difícil dessas duas naturezas. (...) Há mais de sessenta anos, John Grierson forneceu uma das definições mais clássicas de documentário. Segundo ele, documentário era "o tratamento criativo da realidade”. Detendo-nos no substantivo tratamento, notamos que a palavra indica uma transformação; quanto ao adjetivo, basta notar, como contraponto, que Grierson não fala em tratamento especular da realidade, mas em tratamento criativo (SALLES, 2005, p. 62).

Contudo, no que diz respeito à natureza documental dos filmes, o aparentemente simples conceito the feeling of being there, ou "a sensação de estar lá", de Leacock, procura dar conta de uma pergunta fundamental que ele próprio coloca, e que pode ser feita à Duschenes no contexto da pesquisa, "Afinal, o que um cineasta faz?":

Para mim, quase sempre tem sido um desejo intenso de compartilhar uma experiência com os outros. Como posso fazer você vivenciar alguns aspectos daquilo que eu estou vivenciando? Não a totalidade. Não "toda a verdade". Mas, em termos 
precisos, compartilhar aspectos daquilo que vi e ouvi quando segurava minha câmera, organizado de um jeito que você terá a sensação de estar lá. E, claro, será subjetivo. Não há nada errado com a subjetividade. Aquilo que acontece em torno de nós é por demais complexo e multifacetado para que sejamos objetivos num sentido científico. A física não é poesia, mas a poesia pode encarnar a verdade (LEACOCK, 1996).

Mais atento do que Grierson à existência de um espectador no final da linha de produção, há nas palavras de Leacock uma preocupação com questões acerca do aspecto autoral no documentário, do compartilhamento de uma experiência vivida por meio da câmera e a organização do mundo na mesa de montagem que visa estabelecer um canal de comunicação com o espectador que privilegia o plano sensível. Assim como aconteceu no Cinema Direto norte-americano, a "sensação de estar lá" foi um dos principais agentes da produção de Duschenes, especialmente em seus filmes de viagem. "Estar" em um lugar físico, sem dúvida, como um país distante, fora do alcance da maior parte de seus alunos, mas, essencialmente, "estar" nesse lugar metafísico a que alude Leacock, onde é possível compartilhar uma verdade não factual, mas poética, que aproxima as pessoas pelo tempo da projeção de um filme mas, sobretudo, de sua permanência na memória de quem o assistiu.

Em O cinema ou o homem imaginário, Edgar Morin tira o espectador de uma posição passiva ou de mero receptor de imagens, noção que encontra uma ressonância com os procedimentos de Duschenes em relação aos seus alunos. Morin cita a inteligibilidade universal suscitada pelo cinema que se traduz por uma universalidade que, por sua vez, representa uma nova linguagem, um esperanto que não divide as pessoas entre letradas e iletradas: "É isto, o cinema. O que ele tem de interesse e o interessa é o espírito ainda na infância, que carrega dentro dele, ainda indistinta e misturada, a totalidade humana" (MORIN, 2013, p. 201).

Falar em totalidade implica na dissolução de fronteiras ou sua transposição, o que nos leva a outro conceito, igualmente coerente com a linha de pensamento que pretendemos construir, o conceito de desterritorialização de Gilles Deleuze e Félix Guattari. No caso dos filmes de viagem de Duschenes, a desterritorialização se aplica tanto fisicamente por conta do contínuo deslocamento geográfico que o acompanhou durante a vida (e dá origem à viagem permanente que inspirou o título deste projeto), como no sentido efetivamente pensado por Deleuze e Guattari, ou seja, as fronteiras imateriais, aqui representadas pelas fronteiras pessoais e culturais que Duschenes atravessou, notadamente por meio das imagens que gerou. Ao comentar a imagem, Georges Didi-Huberman alude a esse conceito no documentário 
Foucault contre lui-même (Foucault contra Foucault, 2014), de François Caillat, e abre espaço para refletirmos sobre a articulação que Duschenes fez entre os filmes que produziu e sua atuação como professor, o surgimento do professor-cineasta com uma metodologia particular e seu impacto sobre seus alunos:

O fato de transgredir constantemente, de passar, atravessar fronteiras é o que devemos absolutamente lembrar. É fundamental. Eu diria que uma das características daquilo que chamamos de "imagem" é o fato de ela poder atravessar fronteiras. Uma imagem atravessa fronteiras. Um selo, por exemplo, foi feito para atravessar fronteiras. As imagens, as ideias, a construção de saberes, se elas se territorializam, estamos perdidos. É preciso desterritorializar.

Mas, retomando a pergunta que Leacock faz acima, é possível jogar com as palavras e indagar, "Afinal, o que faz de um filme um documentário?" Mais um conceito de Odin se apresenta como ferramenta de análise eficaz, o de leitura documentarizante. Ele se articula em torno de três eixos, denominados de sistema interativo de três actantes. Em primeiro lugar, há o filme propriamente dito, que traz a noção de documento, seja ele um documentário ou uma obra dita de ficção. Mais do que uma simples raiz etimológica, o filme é documento, não por conta da simples oposição entre realidade e ficção, mas no sentido de ser inerente a um filme documentar aquilo que ele representa ou enuncia, sejam suas referências reais ou não. Em segundo lugar, há uma instituição ou um indivíduo que constituem as modalidades de produção, desenhando limites e direcionando o modo de leitura. Por fim, há o leitor, cuja leitura individual será resultado não apenas de um ponto de vista pessoal e subjetivo, mas de sua conjugação com fatores contidos nos dois actantes precedentes. A voz, ou o discurso de Duschenes em sua obra pode ser estudado segundo a definição de Odin de "Enunciador", que afirma, "De fato, o único critério que, nos parece, deve ser mantido para caracterizar aquilo que advém na hora de executar a leitura documentarizante é que o leitor constrói a imagem do Enunciador, pressupondo a realidade desse Enunciador" (ODIN, 2012, p. 18).

Alguns modos de produção documentarizante são particularmente flagrantes nos filmes. O aspecto documental daquilo que Duschenes registra está relacionado tanto ao mundo que de fato o circunda como a ideia que ele faz desse mundo. Portanto, seus filmes documentam a vida que ele constrói materialmente (a família, a casa no bairro do Sumaré, etc.), mas, sobretudo, a vida que ele fabrica narrativamente com suas imagens em torno de temas que lhe são caros (sobrevivência, felicidade, amor, a arte como salvação, etc.). É neste ponto que os filmes adquirem 
uma dimensão ampliada de interesse. O leitor nunca duvida que está diante de um eu-origem real e aceita o contrato com esse enunciador: "O que estabelece a leitura documentarizante é a realidade pressuposta de Enunciador, e não a realidade do representado" (ODIN, 2012). Ao incluir o leitor, efetua-se o espelhamento desse texto composto por imagens. No caso, este dado é especialmente relevante, pois, até o momento, os espectadores dos filmes são quase que exclusivamente a família e os ex-alunos de Duschenes. Outra referência se faz necessária dentro do quadro teórico para melhor darmos conta de ponderar esse espelhamento, O sujeito na tela, de Arlindo Machado: "O problema, portanto, é explicar o funcionamento de um narrador implicado na história e os efeitos de posicionamento do espectador daí derivados" (MACHADO, 2007, p. 85).

Abordar filmes amadores implica no risco de se lançar mão de uma bibliografia "adaptada", ou seja, a partir de conceitos mais amplos ou oriundos de uma reflexão sobre outras áreas mais constituídas da produção audiovisual, fazer com que o acervo Duschenes caiba dentro desses conceitos. A fim de mitigar o risco desse desvio, até o momento, as referências bibliográficas têm como base, fora os já citados textos de Machado, a coletânea organizada por Odin, Le film de famille - usage privé, usage public, que reúne, além do já citado Eric de Kuyper, contribuições de Jean-Pierre Ezquenazi com L'effet film de famille e Le film de famille comme document historique, de Susan Aasman, obras fundamentais para a condução deste trabalho. Essas referências dialogam com reflexões sobre o mesmo tema de Colette Piault, que contribui com um olhar formado pela antropologia visual que, mesmo se de maneira informal, permeia a produção de Duschenes e a coloca em relação com a de Jean Rouch, presente na bibliografia com seus textos reunidos por Jean-Paul Colleyn em Jean Rouch - Cinéma et Anthropologie. Recorremos também aos artigos dos autores que integram a coletânea organizada por Patrícia Rebello e Rafael Sampaio, Péter Forgács - arquitetura da memória, entre eles, Consuelo Lins, Thais Blank, Beatriz Rodovalho, além do próprio Forgács, que trabalham com a articulação das dimensões individual e histórica da memória.

O paralelo com os filmes de Péter Forgács se dá na medida em que estes também trazem em seu bojo aspectos de um deslocamento temporal e espacial causado pelo advento brutal de uma guerra que dizima famílias, sonhos, sociedades inteiras. Por esse motivo, paira uma sombra tanto sobre a tranquilidade dos personagens de Forgács como sobre os de Duschenes. De um ponto de vista presente - o único que podemos ter ao analisarmos os filmes hoje e que conta com o filtro do recuo dos anos -, os personagens de Duschenes e Forgács parecem, em certos momentos, ter cons- 
ciência de que exercem o direito à felicidade nas brechas da tragédia: alguns antes de seu advento, como a Miss Universo 1929, Lisl Goldarbeiter, de Forgács; outros durante e depois, como, na Hungria, os donos dos cachorros dachhund Dusi e Jenö e, no Brasil, os Duschenes. Como não enxergar uma relação entre a família Bartos e a família Duschenes, supostamente alheias aos acontecimentos do mundo? Trata-se, contudo, de uma tranquilidade de contornos urgentes e fugidios na medida em que não é recebida gratuitamente, mas conquistada ao risco da própria vida e, mesmo assim, não está plenamente assegurada. Esta é a verdadeira narrativa que subjaz às imagens dos filmes de Forgács e Duschenes e lhes confere uma qualidade dramática.

Existe, no entanto, uma diferença fundamental entre os dois realizadores: Forgács trabalha com found footage, ou seja, um material que não gerou. Ele se apodera de filmes que terceiros fizeram com o intuito de registrar momentos em família. Portanto, Forgács não está presente quando as filmagens acontecem. Somente décadas mais tarde, por meio da montagem na qual articula efeitos visuais, trilha musical e comentário literário, constrói uma narrativa que coloca os personagens em relação com o mundo histórico em que viveram de um ponto de vista presente. Se Duschenes enuncia desde o instante em que empunha a câmera, Forgács é um enunciador remoto da situação de filmagem, sendo essencialmente um enunciador-montador.

Duschenes detém os meios de produção, cria a circunstância da tomada, controla a situação de filmagem e, por mais que apareça pouco nos filmes, não se omite. Pelo contrário, desde o extracampo é parte integrante da situação que filma. Forgács enuncia por um viés de denúncia poética, apontando para vidas e fatos que, na maior parte, se desenrolaram antes dele nascer, ao passo que Duschenes tem uma relação pessoal e direta com aquilo que o espectador vê: ao filmar e montar a vida que ele por pouco não perdeu, reverte a sentença de morte que um dia se abateu sobre ele. Assim, inversamente ao toureiro Manolete que morre para sempre em Morte todas as tardes, Duschenes e sua família podem viver todas as tardes na tela, no que André Bazin chama de "uma eternidade material" (XAVIER, 2003, p. 134).

Podemos citar outras referências bibliográficas pertinentes, como André Huet, que assina o texto Propos d'un passeur d'images dentro da coletânea organizada por Nathalie Tousignant, da Universidade Saint-Louis, em Bruxelas, Le film de famille - actes de la rencontres autour des inédits tenue à Bruxelles em novembre 2000. Para estudarmos os filmes que Duschenes realizou sobre Maria e a dança, consideramos a pesquisa que Cristian Borges vem desenvolvendo acerca da representação do corpo e do movimento no cinema. Esse conjunto de referências fornece os subsídios para a problematização em torno da questão dos filmes amadores, tornando possível 
analisar e interpreta-los a partir de uma bibliografia adequada.

No entanto, talvez um dos motores essenciais deste estudo seja a compreensão não somente racional, mas afetiva do pesquisador com relação ao seu objeto. Pois, longe de ser um gesto isolado e indiferente, a análise é um processo que logra resultados melhores quando há aproximação entre essas duas entidades, pesquisador e objeto. Isto porque a análise se faz primordialmente entre o que o pesquisador sabe e aquilo que o objeto diz, que é o que o pesquisador não sabe. O resultado dessa fusão é um novo saber e o discurso que o traduz é fruto de uma análise que, desde seu início, acompanhou e respeitou a poética de seu objeto. Eis o limite, o valor desse discurso, que uma vez estabelecido, como um palimpsesto, estará pronto para ser reescrito, indefinidamente, a cada nova análise. Dessa maneira, concluímos, ao menos por ora, com as palavras daquele que é não apenas uma referência bibliográfica e filmográfica para pesquisa dos filmes de Herbert Duschenes, mas um fio condutor poético para seu desenvolvimento, Jonas Mekas, em Walden - Diaries, notes and sketches (Walden - Diários, notas e esboços, 1964-68/1968-69): "Eu vivo, portanto eu faço filmes. Eu filmo, portanto eu vivo. Vida. Movimento. Eu faço filmes amadores, portanto eu vivo. Eu vivo, portanto eu faço filmes amadores."

\section{Referências bibliográficas}

BORGES, C. "Mais perto do coração selvagem (do cinema)". In: GONÇALVES, O. (org.). Narrativas sensoriais: ensaios sobre cinema e arte contemporânea. Rio de Janeiro: Circuito, 2014, p. 41-59.

COLLEYN, J.-P. (org.). Jean Rouch: cinéma et anthropologie. Paris : Cahiers du Cinéma; INA, 2009.

DELEUZE, G.; GUATTARI, F. Qu'est-ce que la philosophie? Paris: Minuit, 1991.

DUSCHENES, H. Autobiografia. Curitiba: manuscrito, 2003.

LEACOCK, R. "Filmmaking - What we mean by it". In: Essays, 1996, disponível em www.richardleacock.com. Acesso 4/02/2016.

. "The art of home movies or To hell with the professionalism of television and cinema producers". In: Essays,1993, disponível em www.richardleacock.com. Acesso 4/02/2016.

LÉVI-STRAUSS, C. Tristes Tropiques. Paris : Plon, 2011.

LINS, C.; BLANK, T. "Filmes de família, cinema amador e a memória do mundo". Significação, n. 37, 2012, p. 53-74. Disponível em http://www.revistas.usp.br/ 
significacao/article/view/71254. Acesso 3/04/2015.

MACHADO, A. "Novos territórios do documentário". Doc On-line Revista Digital de Cinema Documentário. Campinas, n. 11, dez. 2011, p. 5-24. Disponível em http://www.doc.ubi.pt/11/dossier_arlindo_machado.pdf. Acesso 31/10/2015.

O sujeito na tela: modos de enunciação no cinema e no ciberespaço. São Paulo: Paulus, 2007.

MEKAS, J.; MOURÃO, P. (org.). Jonas Mekas. São Paulo: Centro Cultural Banco do Brasil; Pró-reitoria de Cultura e Extensão Universitária - USP, 2013.

MORIN, E. Le cinema ou l'homme imaginaire: essai d'anthropologie. Paris: Les Editions de Minuit, 2013.

ODIN, R. "Filme documentário, leitura documentarizante". Significação, n. 37, 2012, p. 10-30. Disponível em http://www.usp.br/significacao/pdf/37_odin.pdf. Acesso 30/11/2015.

. "El film familiar como documento - Enfoque semioprágmatico". Archivos de la Filmoteca, Valencia, v. II, n. 57-58, 2007, p. 197-217. Disponível em http:// www.archivosdelafilmoteca.com/index.php/archivos/article/view/193/196. Acesso 6/01/2016. Klincksieck, 1995.

PIAULT, C. "Films de famille et films sur la famille". Journal des Anthropologues. n. 94-95, p. 285-298, fev. 2009. Disponível em http://jda.revues.org/1912. Acesso $6 / 01 / 2016$.

REBELlO, P.; SAMPAIO, R. (orgs.). Péter Forgács: Arquitetura da memória. São Paulo: Centro Cultural Banco do Brasil, 2012.

SALLES, J. M. "A dificuldade do documentário". In: MARTINS, J. Souza; ECKERT, C.; NOVAES, S. C. (orgs.). O imaginário e o poético nas ciências sociais. Bauru, SP: EDUSC, 2005, p. 57-71.

TOUSIGNANT, N. (org.). Le film de famille - Actes de la rencontre autour des inédits tenue à Bruxelles en novembre 2000. Bruxelles: Publications de facultés Universitaires Saint-Louis, 2004.

XAVIER, I. A experiência do cinema: Antologia. 2ª ed. Rio de Janeiro: Edições Graal, 2003.

\section{Referências webgráficas}

http://sites.itaucultural.org.br/ocupacao/\#!/pt/artistas/641/maria-e-herbertduschenes/1/inicio. Acesso 30/04/2016.

submetido em: 26 fev. 2016 | aprovado em: 21 jul. 2016. 